\title{
Marrow purging in autologous bone marrow transplantation for mexican children with acute leukemia: a successful treatment
}

Vázquez-Meraz E*, Montaño-Figueroa EH**, Mendoza-García E**, Arellano-Galindo ${ }^{* * *}$, Rosas-Cabral $A^{* * * *}$.

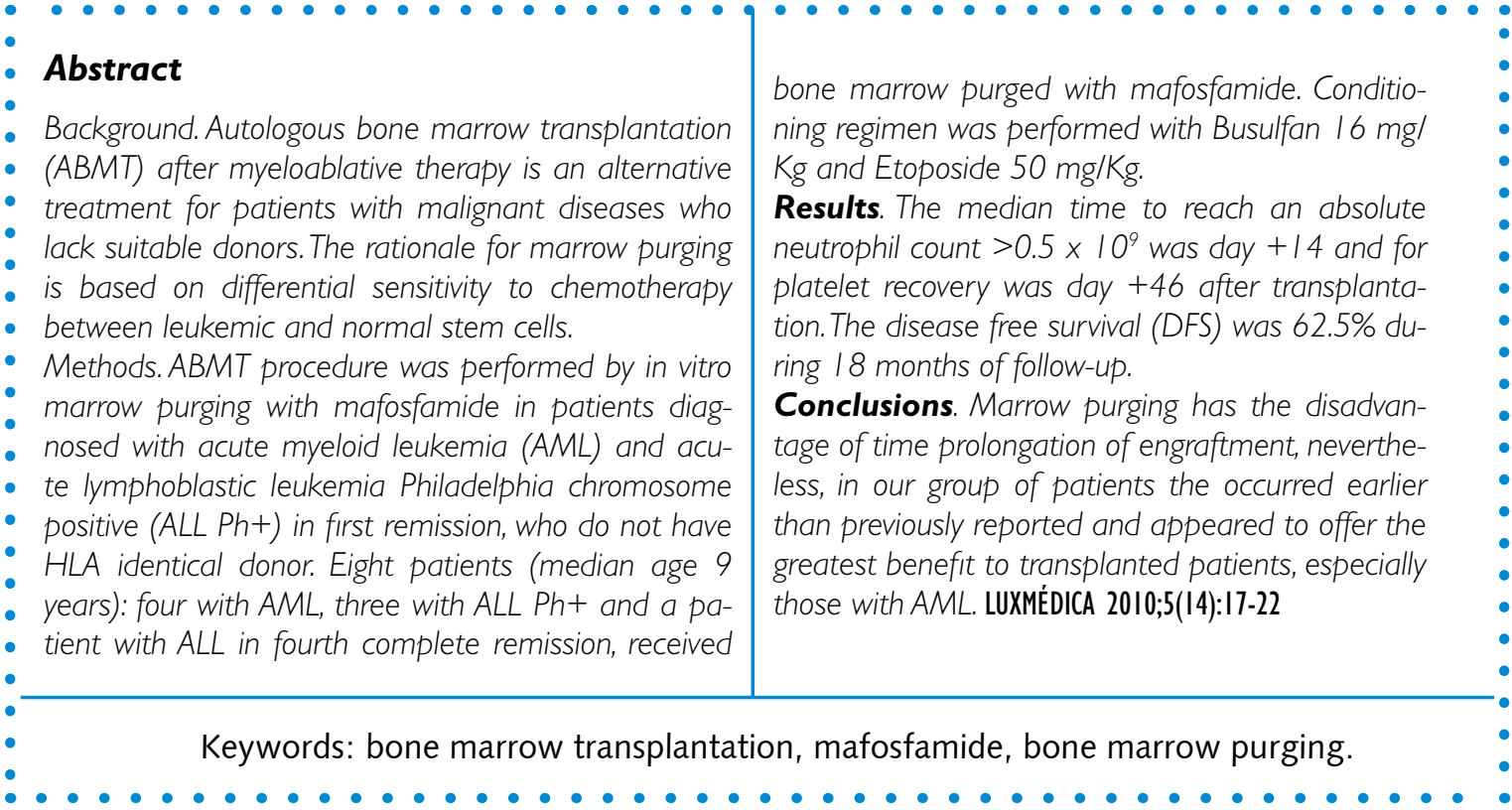

\section{Introduction}

Treatment of childhood acute leukemia has achieved important advances during the last decade. Currently, more than $70 \%$ of children with ALL are alive and disease free at 5 years of the end of the treatment. ${ }^{1}$ Certain forms of acute childhood leukemia have

\footnotetext{
* Bone marrow transplantation service. Nuevo Sanatorio Durango Hospital México City.

** Department of Hematology General Hospital of México. México City.

*** Department of Hematology Children's Hospital of México. México City.

**** Department of Medicine Universidad Autónoma de Aguascalientes.
} 
$90 \%$ probability of cure. On the other hand, in the treatment of $\mathrm{AML}$, there is still an elevated frequency of therapy resistant. Despite the combination of chemotherapy, it has no significant effect on outcomes ${ }^{2}$. Some studies, inform that intensive post remission therapies with new chemotherapics drugs have showed a $50 \%$ of patient survival at 5 years.

There is, however, evidence that alternative therapies are very much needed in this kind of leukemia. ${ }^{3}$ It has been demonstrated that the combination of chemotherapies in leukemia quickly develop drug resistance resulting in relapse. A solution to this problem is the development of more intensive chemotherapy followed by bone marrow transplantation..$^{3,4}$

In childhood $A M L$, chemotherapy results have always been inferior to those in ALL. Thus, in AML, allogeneic bone marrow transplantation was proposed as a primary form of therapy. ${ }^{5}$ AMBT in childhood ALL has been generally confined to patients who relapse from primary therapy, or those who have a very poor response to chemotherapy, that is, patients with high risk $A L L$, for instance $A L L$ $\mathrm{Ph}+{ }^{6}$

Patients, who lack a HLA compatible donor, are candidates for autologous bone marrow transplantation. The role of ABMT in children with $A M L$ and $A L L$ is lees clear that allogeneic transplants; however, in most cases it provides an alternative of treatment, especially in children who relapse after primary chemotherapy. ${ }^{1,5,6}$ There is evidence that $A B M T$ do not present the immunologic graft-versus-leukemia effect such allogeneic transplants, and that reinfused non purged autologous bone marrow may contain leukemic cells. The possibility of graft combination with leukemic cells leading to relapse as shown by gene marker studies for bone marrow led to the development of purging strategies for elimination of residual leukemic progenitors bone marrow autografts. ${ }^{7}$ The rationale for marrow purging is based on differential sensitivity to chemotherapy between leukemic and normal stem cells. Chemical agents like the cyclophosphamide derivatives: 4- Hydroperoxycyclophosphamide (4-HC) and mafosfamide, are the most commonly studied for ex vivo purging. There have been considerable clinical experiences at european centers with the use of mafosfamide for bone marrow purging. It have been used in $A L L, A M L$, chronic myeloid leukemia, non Hodgkin lymphoma, neuroblastoma, as with other pediatric solid tumors. 7, 8,9 The role of autologous BMT has been extensively studied in large part because of the ability to perform this procedure in all patients in remission without regard to availability of a HLA matched sibling donor. 7,10

We herein report the results of autologous BMT after in vitro purging with mafosfamide in children diagnosed with AML or ALL $\mathrm{Ph}+$ in first remission, and who do not have HLA identical donor. 


\section{Material and Methods}

Patients. Eight children four with $\mathrm{AML}$ and four with ALL CrPh+ all of them in first remission and without a HLA identical donor were enrolled in this protocol. The median age was 9 years (3-12 years). Two female and six males. Table 1 summarized the characteristics of the patients. We obtained an informed consent from the parents of all patients in order to receive the purging autografts.

\section{Table I}

\section{Description of patient characteristics, follow-up and special observations}

\begin{tabular}{|rlrrrrll}
\hline Age & Diagnosis & Neutrophil & Platelet & State & Follw-up & Observation \\
\hline (years) & Engraftment & Engraftment & (Months) & & & \\
\hline 9 & AML-M1 & +13 & +45 & Alive & 36 & None \\
\hline 12 & AML-M4 & +14 & +65 & Alive & 24 & Autoantibodies \\
\hline 8 & AML-M4 & +15 & +28 & Alive & 22 & Alloinmunization \\
\hline 9 & AML-M1 & +20 & +65 & Alive & 12 & None \\
\hline 3 & ALL CrPh+ & +14 & +40 & Died & 26 & Relapse \\
\hline 8 & ALL CrPh+ & +13 & +50 & Died & 8 & Relapse \\
\hline 12 & ALL CrPh+ & +9 & +33 & Alive & 12 & None \\
\hline 12 & ALL 4th CR & +11 & +76 & Died & 4 & Relapse \\
\hline
\end{tabular}

Abbreviations:

*Days post transplantation.

AML: Acute myeloblastic leukemia.

ALL Cr Ph+: Acute lymphoblastic Leukemia, Philadelphia Chromosome Positive.

CR: Complete remission.

\section{Bone marrow collection and processing}

Peripheral blood progenitor cells (PBPC) were first collected in order to have backup in all patients. Bone marrow hematopoietic cells were collected to obtain $>4 x$ $10^{8} / \mathrm{Kg}$ mononuclear cells. The buffy coat was separated by centrifugation and prepared at a cell concentration of $2 \times 10^{7} / \mathrm{ml}$ in RPMI 1640 (GIBCO, Grand Island, NY USA) and the hematocrit was adjusted to $15-20 \%$. Mafosfamide-lysine ( Asta-Z 5767, ASTA Pharma, Bielefeld, Germany) was added to the cell suspension to obtain a final concentration of $50 \mu \mathrm{g} / \mathrm{ml}$. Cells were incubated with mafosfamide at 37 ${ }^{\circ} \mathrm{C}$ for $30 \mathrm{~min}$, and then rapidly cooled to $4{ }^{\circ} \mathrm{C}$. Cells were washed twice and re-suspended at a final concentration of $2 \times 10^{8} /$ $\mathrm{kg}$ in RPMI 1540 median in 5\% autologous plasma and $10 \%$ dimethyl sulfoxide (DMSO), and then frozen in a controlledrated freezer; finally they were transferred to liquid nitrogen. At time of autologous reinfusion, each bag was thawed in $37^{\circ} \mathrm{C}$ water bath and immediately infused intravenously. The median cell dose was $2 \times 10^{8}$ nucleated cells $/ \mathrm{kg}$ of body weight. 


\section{Preparative chemotherapy}

Busulfan $4 \mathrm{mg} / \mathrm{Kg}$ was administered orally daily during four days (days -7 to -4 ). Etoposide $50 \mathrm{mg} / \mathrm{kg}$ was administered by intravenous infusion on day -3 . Bone marrow cells were infused on day 0 .

Supportive care

Patients were hospitalized in private rooms with high efficiency particle air (HEPA) filtration. Infection prophylaxis was performed with acyclovir (750 mg/m² BS / day), trimethoprime/sulfamethoxysol ( 5 $\mathrm{mg} / \mathrm{kg} /$ day) administered only on weekends, fluconazol $(6 \mathrm{mg} / \mathrm{kg} /$ day). Every two weeks the patients received $400 \mathrm{mg} / \mathrm{kg}$ of Gammaglobulin for a total of eight doses. Platelets were transfused to maintain a platelet count greater than $20.000 / \mu \mathrm{l}$.

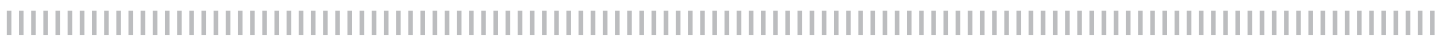

\section{Results}

Four patients with $A M L$, three with $A L L$ $\mathrm{Cr} \mathrm{Ph}+$ in first complete remission and one with $A L L$ in fourth complete remission were enrolled. All patients without a HLA identical donor available. The age of the patients ranged from 3 to 12 years, median 9 years. The patients with ALL $\mathrm{Cr} \mathrm{Ph}+$ were treated previously to the transplant with high risk chemotherapy as described the XIII protocol from CCG group. ${ }^{8} \mathrm{~Pa}-$ tients with $\mathrm{AML}$ underwent therapy with daunorrubicin and cytarabine, followed by high doses of Ara- $\mathrm{C}$ and etoposide for two to four courses. Patient proceeded from remission to transplantation in a median of 6 months (range 5 to 12 months).

Mean time of engraftment was day +14 post-transplant $(+9$ to +20 ) to achieve an absolute neutrophil count greater than
$0.5 \times 10^{9} / \mathrm{L}$. Platelet transfusion support was required for a mean time of 46 days after transplantation in order to maintain a platelet count greater than $20.000 / \mu$ l. Only one patient required platelet transfusion support for longer than 6 months.

The median number of transfused red blood units was four (3 to 6). Non-hematologic toxicity affected primarily mucous membranes, skin and gastrointestinal tract. Patients received parenteral nutrition for a median of 10 days and narcotic analgesic for a median of 7 days after transplantation. 35 days were the median of time of hospitalization (30-50 days) after day 0.

Of the three patients with ALL $\mathrm{Cr} \mathrm{Ph}+$ two relapsed and died after 8 and 26 months following transplantation. The disease-free survival is $62.5 \%$ in a follow-up of 18 months (4-26 months).

\section{||||||||||||||||||||||||||||||||||||||||||||||||||||||||||||||||||||||||||||||||||||||||||||||||||||||||||||||||||||||||}

\section{Discussion}

Mafosfamide, a cyclophosphamide derivative, has been successfully used for bone marrow purging in order to reduce contamination with tumor cells. The properties of pharmacologicals agents that are considered most suitable for ex vivo bone marrow purging include: antitumor cytotoxicity that is cell cycle non-specific, ability to kill clonogenic tumor cells, lack of toxicity to normal bone marrow progenitors, especially pluripotent hematopoietic cells, lack of cross-resistance with prior drug regimens, solubility, in vitro activity and ease of removal or inactivation. 7,12 Several groups of investigators have demonstrated the clinical feasibility of mafosfamide purged ABMT with results that show improved relapse-free survival rates in subsets of patients with $A M L$, and possibly. ${ }^{7,8,10,13}$

The most extensive clinical experience with mafosfamide purging has been reported by Gorin et al. ${ }^{14}$ representing the retrospectively analyzed experience of the 
European Cooperative Group for Bone Marrow Transplantation (EBMT) in patients with $A M L$. The first results included 263 patients and were then updated to include 2 additional years of follow-up and a total of 919 cases treated at 55 centers. ${ }^{15}$ The relapse-free survival in patients with mafosfamide purged marrow appeared to be significantly better than in patients with nonpurged marrow. The probability of relapse within 3 years was only $23 \%$ in the recipients of mafosfamide purged marrow compared to $55 \%$ in the recipients of unpurged marrow. ${ }^{15}$

Carlo-Stella et al. ${ }^{16}$ investigated the effects of mafosfamide treatment on the proportion of Philadelphia chromosome positive cells in the bone marrow of patients with $\mathrm{Ph}+\mathrm{CMI}$. The ability of mafosfamide treatment to increase the proportion of Philadelphia negative cells was observed in only 6 of the 15 tested cases. These results suggest that prescreening the bone marrow for sensitivity of $\mathrm{Ph}+$ cells to mafosfamide may proceed to be useful for predicting those patients who may benefit from the purging of bone marrow with mafosfamide, and probably this test could be realized for the patients with $\mathrm{ALL} \mathrm{Cr} \mathrm{Ph}+$.

A problem with purged bone marrow is the prolonged regeneration times for neutrophils and platelets. It had been observed in several studies, with regeneration period on neutrophils between 16 to 250 days (media 26 days), and platelets between 16 to 740 days (media 74 days), especially in AML patients. ${ }^{17}$ However, these times were shorter in our group of patients, since the neutrophil engraftment was observed in the day +14 ( range +9 to +20 ) and platelet engraftment in day +46 (range +28 to +76 ) after transplantation.

Gorin et al. ${ }^{14}$ showed that the best results in vivo are achieved when the number of CFU-GM collected before the purging are higher than $5.46 \times 10^{4} / \mathrm{Kg}$, which correlated with a low transplant-related mortality. These results correlated with our experience (unpublished data).

The overall role of aggressive myelosuppressive chemotherapy for children with $A M L$ is now firmly established. Studies have documented improved overall survival rate using intensified treatment in the induction as well as in the postremission phase. This aggressive approach, however, is associated with increased morbidity and mortality, primarily due to infection and bleeding caused by prolonged myelosuppression. One major limitation of the previous randomized studies has been the use of less aggressive forms of post-remission chemotherapy compared with current standards. It could be discussed that other preparative regimens with high doses of chemotherapy may improve autologous BMT outcome, but none has been tested in a large number of patients or compared with aggressive chemotherapy in a randomized fashion. ${ }^{18}$

The major problem with the EBMT studies of mafosfamide is that the patients groups with purged and unpurged BM were not randomly assigned to exclude the possibility of selection. Therefore, the benefits of mafosfamide purging may need further confirmation, which would be better accomplished by a prospectively randomized clinical trial, especially in children. In our experience, the complications related to this kind of transplant are not severe, therefore, we conclude that ABMT with mafosfamide purging is a recommended therapeutic approach for children with AML.

\section{Acknowledgements}

The authors would like to thank Mr. Ruben Siedner of the University of Tübingen, Tübingen Germany, for his technical laboratory help. 


\section{References}

1 Kersey John H. Fifty years of studies of the biology and therapy of childhood leukemia. Blood 1997; 90(11): 4243-4251.

2 Wells RJ, Woods WG, Buckley JD et al. Treatment of newly diagnosed children and adolescents with acute myeloid leukemia: a children cancer group study. J Clin Oncol 1994; 12: 2367-2370.

3 Pitter J, Creutzig V, Reiter A, Riehm H et al. Childhood leukemia: Cooperative Berlin-Frankfurt-Munster trials in the Federal Republic of Germany. J Cancer Res Clin Oncol 1990; 116: 100-106.

4 Burnett AK, Goldstone AH, Richard $M$ et al. Randomized comparison of addition of autologous bone marrow transplantation to intensive chemotherapy for acute myeloid leukemia in first remission: results of MRC AML 10 trial. Lancet 1998; 215 (7): 700708.

5 Woods WG, Nuedorf S, Gold S et al. Aggressive post remission chemotherapy is better than autologous bone marrow transplantation and allogeneic BMT is superior to both in children with acute myeloid leukemia. Proc ASCO 1996; 15: 368-371.

6 Forman SJ, O'Donell MR, Nademaee AP et al. Bone marrow transplantation for patients with Philadelphia chromosome-positive acute lymphoblastic leukemia. Blood 1987; 70: 587-591.

7 Murgo AJ, Weinberg BB. Pharmacological bone marrow purging in autologous transplantation focus on the cyclophosphamide derivatives. Critical Reviews in Oncology/Hematology 1993; 14: 41-60.

8 Rivera GK, Raimondi SC, Hancock ML et al. Improved outcome in childhood acute lymphoblastic leukemia with reinforced early treatment and rotational combination chemotherapy. Lancet 1991; 337: 6166.

9 Uckun FM, Ramarkrishnan S, Haag D, Houston LL. Ex vivo elimination of lymphoblastic leukemia cells from human bone marrow. Bone Marrow Transplant 1987; 2: 287-298.
10 Beaujean F, Hartmann O, Pico J et al. Incubation of autologous bone marrow graft with ASTA Z 7557: comparative studies of hematological reconstitution after purged or nonpurged bone marrow transplantation. Ped Hematol Oncol 1987; 4: 105-115.

11 Gorin NC. Autologous bone marrow transplantation in hematological malignancies. Am J Clin Oncol 1991; 14 (supple 1):5-14.

12 Santos GW, Colvin OM. Pharmacological purging of bone marrow with reference to autografting. Clinics Hematol 1986; 15: 67-83.

13 Korbling $M$, Hustein $W$, Fliedner TM el at. Diseasefree survival after autologous bone marrow transplantation in patients with acute myelogenous leukemia. Blood 1989; 74: 1898-1904.

14 Gorin NC, Labopin M, Meloni G et al. Autologous bone marrow transplantation for acute myeloblastic leukemia in Europa: further evidence of the role of marrow purging by mafosfamide. Leukemia 1991; 5 : 896-904.

15 Gorin NC, Aegerter P, Auvert B et al. Autologous bone marrow transplantation for acute myelocytic leukemia in first remission: a european survey of the role of marror purging. Blood 1990; 75: $1606-$ 1614.

16 Carlo-Stella C, Mangoni L, Piovani G et al. In Vitro marrow purging in chronic myelogenous leucemia: effect of mafosfamide and recombinant granulocyte-macrophage colony-stimulating factor. Bone Marrow Transplant 1991; 8: 265-273.

17 Fauth F, Martin H, Sonnhoff S. Purging of G-CSF mobilized peripheral autografts in acute leukemia with mafosfamide and amifostine to protect normal progenitor cells. Bone Marrow Transplantation 2000; 25: 831-836.

18 Woods WG, Neudorf S, Gold S et al. A comparison of allogeneic bone marrow transplantation, autologous bone marrow transplantation, and aggressive chemotherapy in children with acute myeloid leukemia in remission: a report from children's cancer group. Blood 2001; 97 (1): 56-62.

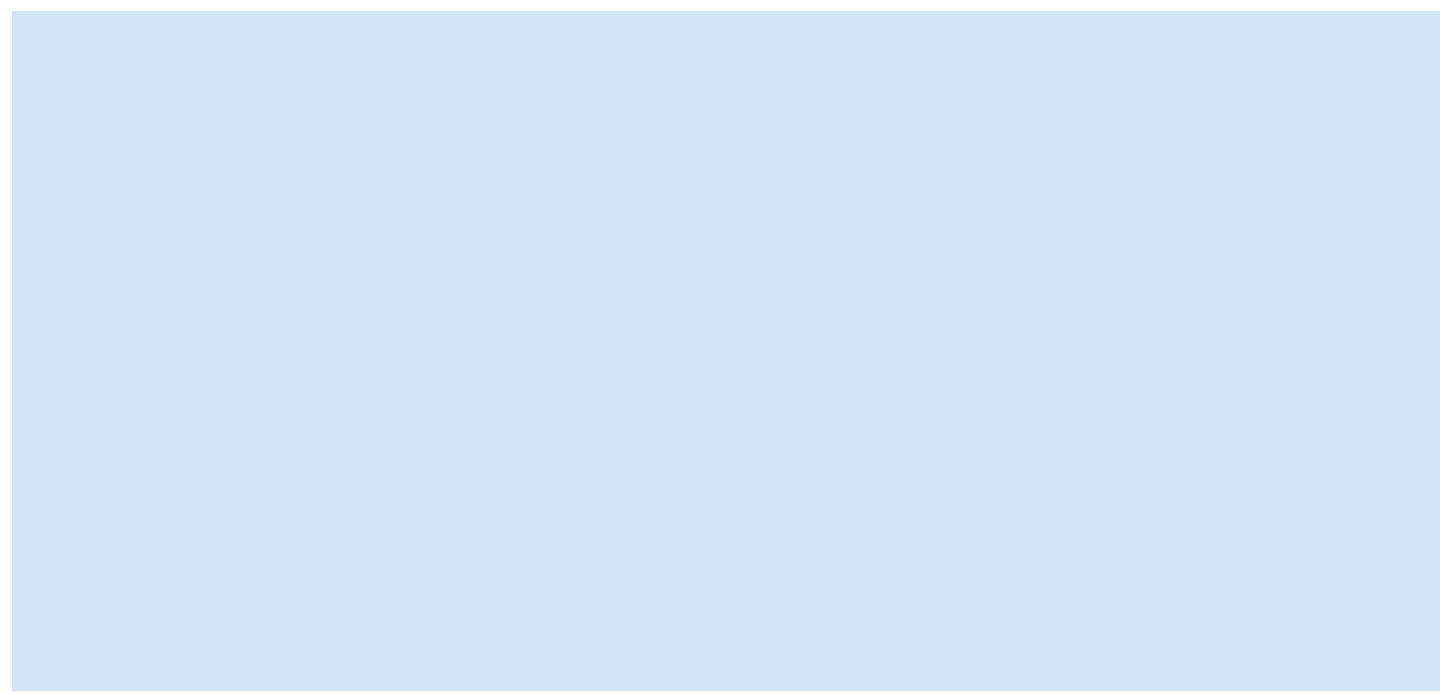

